\title{
Clinical outcomes of the drugs repurposed for the treatment of COVID-19
}

\author{
Nitin Tandon ${ }^{1}$, Vijay Luxami ${ }^{2}$, Runjhun Tandon ${ }^{1}$, and Kamaldeep Paul ${ }^{2}$ \\ ${ }^{1}$ Lovely Professional University \\ ${ }^{2}$ Thapar Institute of Engineering and Technology
}

October 26, 2020

\begin{abstract}
SARS-CoV-2 infections are the most contagious among the three coronavirus infections the world has witnessed till date which have affected almost all parts of the world in millions of population till date since its outbreak in china in Dec. 2019. Moreover, it has severely hit the world economy and therefore there is a dire need to develop the treatment of this deadly disease. Numbers of potential vaccines are in the early or advanced stage of clinical trials. But the development of a vaccine is a very tedious and time consuming task. Therefore, numbers of groups are working on the repurposing of drugs with already known safety and efficacy profile to shorten the time of development of the potential treatment. The main aim of this review article is to summarize the clinical outcomes of the various drugs which have been repurposed for the treatment of COVID-19 associated with SARS-CoV-2.
\end{abstract}

\section{Hosted file}

Manuscript_14_10_2020.pdf available at https://authorea.com/users/370218/articles/488916clinical-outcomes-of-the-drugs-repurposed-for-the-treatment-of-covid-19 